\title{
Redução de Incêndios Florestais na Reserva Biológica de Araras, Rio de Janeiro, Sudeste do Brasil
}

\author{
Fabio Torres Migliari ${ }^{1}$, Izar Aximoff ${ }^{2}$ Massimo G. Bovini ${ }^{3}$
}

Recebido em 21/10/2019 - Aceito em 27/03/2020

\begin{abstract}
Programa de Pós-Graduação Profissional em Biodiversidade em Unidades de Conservação. <ftmbio@hotmail.com>.
2 Escola Nacional de Botânica Tropical, Programa de Pós-Graduação Profissional, Instituto de Pesquisas Jardim Botânico do Rio de Janeiro, Rua Pacheco Leão 915, Rio de Janeiro/RJ, Brasil. CEP: 22.460-030. <izar.aximoff@gmail.com>.

3 Instituto de Pesquisas Jardim Botânico do Rio de Janeiro, Diretoria de Pesquisas, Rua Pacheco Leão 915, Rio de Janeiro/RJ, Brasil. CEP: 22460 030.<mbovini@jbrj.gov.br>.
\end{abstract}

RESUMO - Os incêndios florestais representam uma das maiores ameaças às unidades de conservação (UC) e a toda a biodiversidade contida nessas áreas. Considerando que o bioma Mata Atlântica se encontra extremamente reduzido, impactos que resultem na perda de habitat e de espécies devem ser prevenidos e combatidos de maneira eficiente. O objetivo deste estudo foi traçar o perfil das ações de prevenção a incêndios florestais na Reserva Biológica de Araras (RBA), localizada nos municípios de Petrópolis e Miguel Pereira, no estado do Rio de Janeiro, entre os anos de 2014 e 2018. Por meio da coleta de dados in loco e do levantamento de dados com os gestores da RBA, as ações de prevenção e combate aos incêndios florestais foram identificadas e analisadas. As ações elencadas como educacionais devem ocorrer ao longo de todo o ano, visando alcançar o maior número de pessoas e propriedades nessas áreas. Sobre as ações de monitoramento, algumas demandam maior atenção quanto à forma de execução, aos registros e à periodicidade, por parte da equipe e gestão da UC. Verificou-se no período analisado que, após elevado número de ocorrências atendidas em 2014, nos anos seguintes houve uma diminuição das ocorrências, sugerindo uma possível eficácia das ações e métodos de prevenção adotados pela população vizinha da RBA. Os resultados demonstram que as ações referentes ao Programa de Prevenção e Combate a Incêndios em Florestas contribuem para a proteção integral desta unidade de conservação.

Palavras-chave: Unidades de conservação; zona de amortecimento; Programa de Prevenção aos Incêndios Florestais.

\section{Reduction of Forest Fires in the Araras Biological Reserve, Rio de Janeiro, Southeast Brazil}

\begin{abstract}
Forest fires represent one of the greatest threats to Protected Area (PA) and to all the biodiversity contained in these areas. Considering that the Atlantic Forest biome is extremely reduced, impacts that result in the loss of habitat and species must be prevented and combated efficiently. The present goal of this study was to outline the profile of the wild forest fire prevention and firefighting actions undertaken in the Araras Biological Reserve (RBA) during the 2014 - 2018 period. The Araras Biological Reserve is a Protected Area (PA) in the State of Rio de Janeiro, located in the municipalities of Petropolis and Miguel Pereira, sheltering a remaining and well-preserved vegetation of native Atlantic Forest. After several visits to the RBA to collect data and for field research, the actions/operations were identified and then classified as Educational and Monitoring. Those actions listed as Educational carry information about the importance and danger risks being taken in the presence of fire by the permanent or transient population of both the Buffer Zone area and the neighboring PAs', to be observed along an entire year period, and are meant to reach the areas' highest possible number of persons and properties. About the Monitoring actions, some demand further attention regarding their execution form, registration and periodicity from both the PA's team and managers. During the period under analysis, a decrease has been verified in the number of wild forest fire incidents, suggesting a possible efficiency of both actions and methods adopted the RBA neighboring population. The results demonstrate that those actions referring to the Forest Fire Prevention and Fire Fighting Program contribute to the integral protection of this Protected Area Unit.
\end{abstract}

Keywords: Protected area; buffer zone; Forest Fire Prevention Program. 


\title{
Reducción de Incendios Forestales en la Reserva Biológica Araras, Río de Janeiro, Sudeste de Brasil
}

\begin{abstract}
RESUMEN - Los incendios forestales representan una de las mayores amenazas para las unidades de conservación (UC) y para toda la biodiversidad contenida en estas áreas. Teniendo en cuenta que el bioma del Bosque Atlántico está extremadamente reducido, los impactos que resultan en la pérdida de habitat y especies deben prevenirse y combatirse de manera eficiente. El objetivo de este estudio ha sido lo de trazar el perfil de las acciones para la prevención y combate a Incendios Floresteros en la Reserva Biológica de Araras, entre los años de 2014 a 2018. La Reserva Biológica (REBIO) de Araras es una unidad de conservación (UC) de protección integral ubica da en el estado de Rio de Janeiro, en los municipios de Petrópolis y Miguel Pereira, con un remaneciente del bioma de Mata Atlántica, bien preservado. Atreves de visitas a la REBIO para pesquisas en archivos y en campo, han sido identificadas las acciones, que fueran organizadas em educacionales y de monitoramiento. Las que fueran clasificadas como educacionales cargan informaciones sobre los cuidados y peligros en presencia de fuego, a la población que habita, o frecuenta la área de la zona de amortiguamiento y UCs vecinas, y que debe ocurrir a lo largo del año entero, visando alcanzar el más grande número posible de personas y propiedades en esas áreas. Acerca de las acciones de monitoramiento, algunas demandan atención mayor cuanto a la forma de ejecución, de registros y de periodicidad, de parte del equipo y de la gestión de la UC. En el período analizado se ha verificado una diminución en el número de ocurrencias de incendios floresteros, sugiriendo una posible eficacia de las acciones y métodos adoptados para la concientización de la población ubica da al rededor de RBA. Los resultados demuestran que las acciones referentes al Programa de Prevención y Combate a Incendios Floresteros contribuyen para la protección integral de esta unidad de conservación.
\end{abstract}

Palabras clave: Unidades de conservación; zona de amortiguamiento; Programa de Prevención a Incendios Floresteros.

\section{Introdução}

A perda da biodiversidade e a degradação do ambiente estão entre as principais consequências dos incêndios florestais, além dos prejuízos econômicos e sociais. Quando os incêndios florestais ocorrem no bioma Mata Atlântica, já devastado e com forte pressão antrópica (Rezende et al. 2018), esses impactos são amplificados. Mesmo no interior das unidades de conservação (UCs), onde existem regras de proteção contra sua ocorrência, os incêndios florestais acabam por ser frequentes e de difícil controle e prevenção (Koproski et al. 2004, Aximoff \& Rodrigues 2011, Aximoff 2011, Tebaldi et al. 2013, Aximoff et al. 2016a, Torres et al. 2019). Apesar das consequências negativas e dos esforços de prevenção e combate, que incluem até mesmo o uso do fogo (i.e. queimada prescrita e aceiros negros), as ocorrências de incêndio têm aumentado em todo o Brasil, sendo que o Rio de Janeiro foi o segundo estado brasileiro com maior número de ocorrências nos últimos anos (Lima et al. 2018).

As principais causas de origem dos incêndios florestais nas UCs têm sido o uso do fogo sem autorização por moradores do entorno ou do interior, para renovação de pastagens $e$ limpeza de terreno (Aximoff 2011, Tebaldi et al. 2013). A soltura de balóes também pode ser um dos motivos desses eventos em unidades de conservação urbanas (Aximoff et al. 2016). Entre os desafios encontrados pela gestão das UCs, estão a prevenção e o combate a incêndios florestais (Bontempo et al. 2011, Collins et al. 2013). Os Programas de Prevenção e Combate a Incêndios Florestais muitas vezes estão inseridos no plano de manejo da própria UC, como ocorre no estado do Rio de Janeiro (Magnanini et al. 2010). Esse Programa deve ser constantemente avaliado, de maneira que as ações preventivas, corretivas e de combate tenham maior eficiência. Neste sentido, o objetivo do trabalho foi identificar as ações preventivas e de combate aos incêndios florestais na Reserva Biológica Estadual de Araras (RBA).

\section{Material e Métodos}

\section{Área de estudo}

A RBA foi criada em 1977, com 3.837,81ha inseridos no domínio da Floresta Atlântica, abrangendo território dos municípios de Petrópolis e Miguel Pereira (Figura 1). Encontram-se em seu interior porções de Floresta Ombrófila Densa Montana (até $1.500 \mathrm{~m}$ de altitude), de Floresta Alto Montana (até $1.800 \mathrm{~m}$ ) e de Campos de Altitude, acima do limite florestal (INEA 2010). 
A RBA contribui com significativo remanescente florestal na composição do mosaico de áreas protegidas na região central fluminense do estado do Rio de Janeiro, além de propiciar estabilidade hidrogeológica para as encostas escarpadas da Serra do Mar (INEA 2010). A UC desenvolve atividades de prevenção e combate aos incêndios florestais, incluindo a realização de palestras e notificações para os moradores do entorno, além de capacitação e treinamento de brigadistas (Figura 2A-G). Em seu interior, existem espécies vegetais endêmicas e presentes nas listas de espécies ameaçadas do estado do Rio de Janeiro (Martinelli et al. 2018) e também do Brasil (Portaria do MMA no 443, publicada em 2014). Uma dessas espécies é a erva rupícola, conhecida como rabo-de-galo (Worsleya rayneri) (Martinelli 1984), que apresenta distribuição restrita a alguns afloramentos rochosos no topo de montanhas que constantemente sofrem com os incêndios (Aximoff 2011).

A zona de amortecimento compreende uma área de 6.684ha (Figura 3), estando prevista no plano de manejo (INEA 2010). De maneira a organizar o planejamento das ações de gestão e principalmente de monitoramento, prevenção e combate aos incêndios florestais, o plano de manejo definiu quatro setores na RBA, considerando tanto seu interior quanto a zona $\mathrm{de}$ amortecimento. Os setores são descritos de acordo com sua fitofisionomia, suas ocupações, características físicas e climáticas, que, por sua vez, são classificadas segundo o Índice de Risco de Incêndio (IRI) em Alto, Médio e Baixo riscos.

Os Setores 1, 2 e 3 apresentam baixo adensamento populacional com pequenas propriedades voltadas à agricultura familiar e a culturas perenes, sendo que, no Setor 3 , existem ainda floriculturas desenvolvidas nas propriedades privadas (INEA 2010). Nos Setores 1 e 2 há também sítios de veraneio. O Setor 4 é o maior de todos, com cerca de 6.300ha, possuindo grande adensamento populacional de residências unifamiliares proletárias (INEA 2010). O Setor 1, devido à presença dominante da gramínea Megathyrsus maximus (Jacq.) B. K. Simon \& S. W. L. Jacobs, espécie com biomassa altamente comburente (Aximoff et al. 2016), é o de maior propensão a incêndios florestais, de acordo com o histórico de foco de calor na região (INPE 2018).

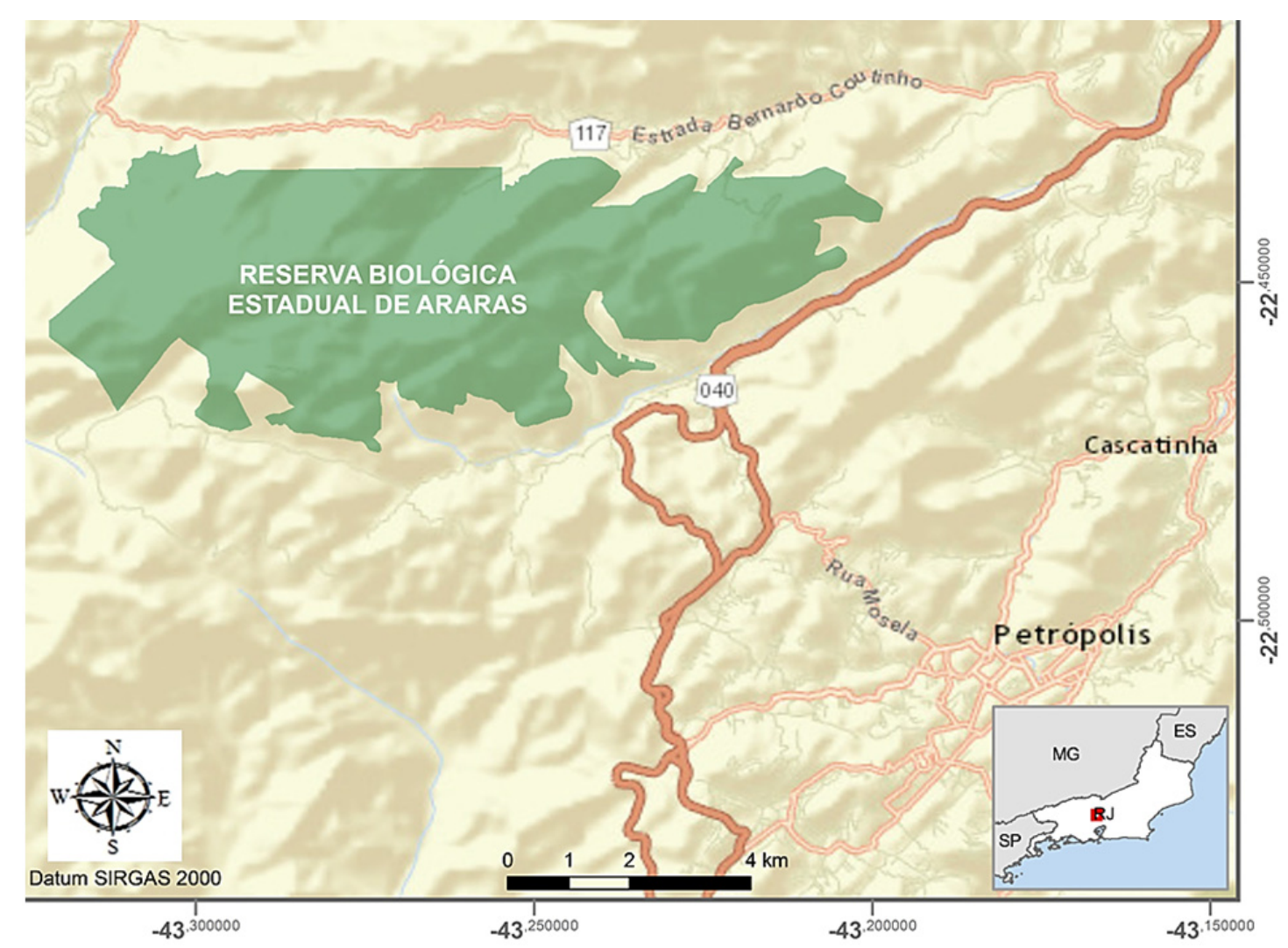

Figura 1 - Localização da Reserva Biológica de Araras, na região serrana do estado do Rio de Janeiro. Fonte: Figura adaptada do site INEA, Plano de Manejo RBA (2010). 

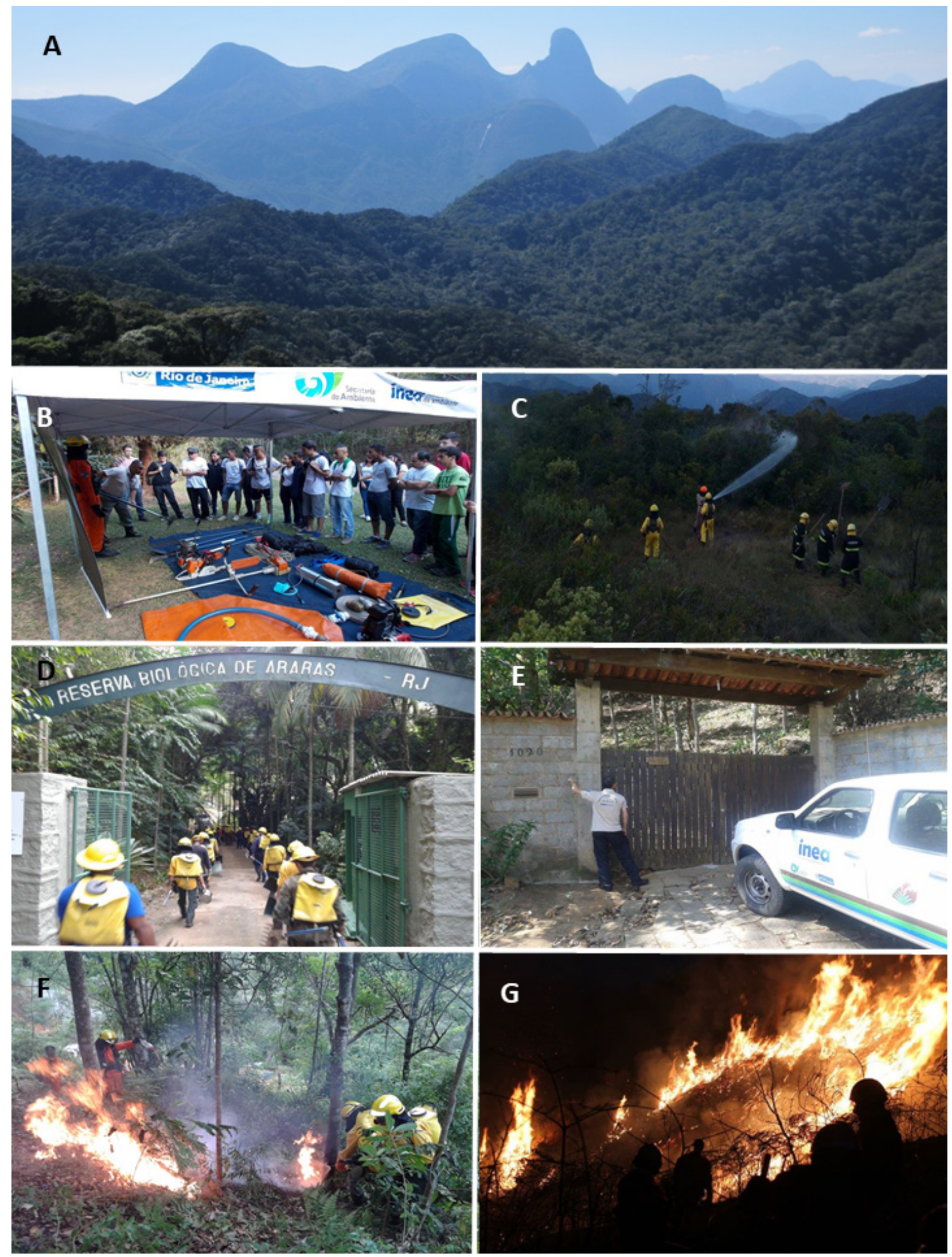

Figura 2 - Incêndios e ações de prevenção e combate na Reserva Biológica de Araras/RJ. A) Floresta $e$ afloramentos rochosos no interior e na zona de amortecimento; B) Palestras para estudantes e moradores do entorno; $\mathrm{C}$ e D) Capacitação e treinamento de brigadistas; E) Entrega de Notificações Preventivas contra Incêndios; $\mathrm{F}$ e G) Combate a incêndio diurno e noturno.

Fonte: Fábio T. Migliari (REBIO Araras). 


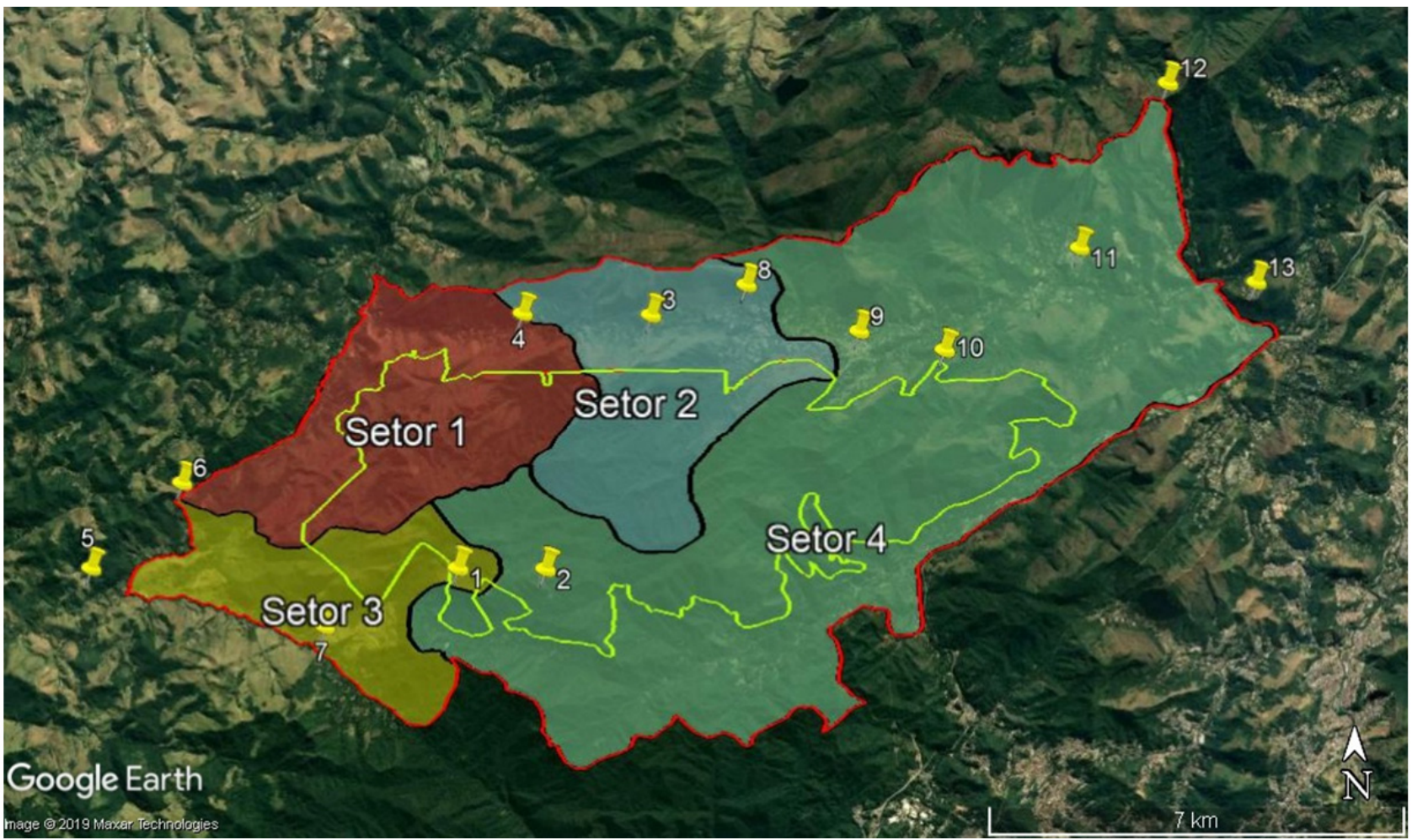

Figura 3 - Zona de amortecimento, delineada pelo vermelho mais externo, ao redor do limite da Reserva Biológica de Araras (no centro da imagem, borda amarela), setores de monitoramento e pontos de visada (ícones amarelos numerados).

Fonte: Figura adaptada INEA, Plano de Manejo RBA (2010), imagem Google Earth (2019).

\section{Obtenção e análise dos dados}

Os dados utilizados na pesquisa compreendem os anos entre 2014 e 2018, sendo que as informações foram obtidas na Sede administrativa da RBA e também coletadas in loco durante ações de prevenção e combate aos incêndios florestais, seguindo as orientações do Plano de Manejo para Prevenção e Combate a Incêndios Florestais (INEA 2010).

Especificamente, as informações relacionadas aos incêndios florestais foram obtidas por meio dos Registros de Ocorrência de Incêndios (ROIs) produzidos quando os incêndios eram detectados e combatidos pela equipe da RBA, na zona de amortecimento ou no interior da Reserva. Posteriormente, as informações obtidas foram detalhadas em relação a aspectos que compõem o combate a incêndios, como localização, época de ocorrência, extensão da área atingida, forma de detecção, além de observações complementares sobre mobilização e deslocamento.

Com a utilização de Sistemas de Informações Geográficas (SIG), foram avaliados os dados pertinentes a focos de calor, de maneira similar a Pereira et al. (2012), obtidos por satélites ambientais para detecção operacional e monitoramento que operam na faixa termal-média de $4 \mathrm{~m}$, utilizados pelo Instituto Nacional de Pesquisas Espaciais (INPE). O sensor Advanced Very High Resolution Radiometer (AVHRR) registra qualquer temperatura acima de $47^{\circ} \mathrm{C}$ em áreas planas e a interpreta como foco de calor.

As ações de prevenção foram analisadas em relação às Notificações Preventivas contra Incêndios (NPIs), às palestras e aos treinamentos de prevenção a incêndios florestais. Outras ações preventivas também importantes, mas que não tinham contato direto com a comunidade do entorno, como sinalização por placas, realização de rondas para avistamento de possíveis focos de incêndio, confecção de aceiros, além do monitoramento de umidade e temperatura, foram consideradas neste trabalho. Identificamos pessoalmente em campo que as 12 placas com dizeres relativos ao uso do fogo e prevenção de incêndios passam por manutenção periódica e estão instaladas nos quatro setores em pontos propensos a incêndios, 
conforme sugerem Santos et al. (2017). As rondas de identificação e avistamento de possíveis focos de incêndio são realizadas por meio de visitas a 13 pontos de acesso facilitado à equipe, onde se podem monitorar todos os setores. Atualmente são mantidos dois aceiros, existentes no interior da $\mathrm{UC}$, de aproximadamente $1 \mathrm{~km}$ de comprimento, com realização de roçada trimestral. Em relação ao monitoramento da umidade e temperatura utilizado para calcular o Índice de Risco de Incêndio entre 2014 e 2017, identificamos a utilização de duas metodologias diferentes, considerando tanto dados de aparelho portátil quanto dados de estação meteorológica fixa, instalada no interior da UC.

\section{Resultados e Discussão}

\section{Incêndios florestais}

O número de ocorrências de incêndio na RBA ( $\mathrm{n}=15)$, com extensão menor que 4 mil hectares, pode ser considerado dentro da média, quando comparado com outras UCs no bioma Mata Atlântica. Por exemplo, no Parque Estadual da Serra do Brigadeiro, cuja área é de 14.984ha, quase cinco vezes maior que a RBA, localizado na região serrana do estado de Minas Gerais, ocorreram 34 incêndios entre 2007 e 2015 (Torres et al. 2018). Já no Parque Nacional de Ilha Grande (78.875ha), no Paraná, ocorreram 52 incêndios entre 1999 e 2003 (Koproski et al. 2004).

Em relação aos anos de monitoramento dos incêndios, identificamos que 2014 foi o ano com maior ocorrência (60\%) e com maiores extensões de áreas (74\%) atingidas (Figura 4). Nesse mesmo ano, foi queimado um total de quase 4 mil hectares de vegetação na região serrana do estado do Rio de Janeiro, com incêndios extensos atingindo, simultaneamente, o Parque Nacional da Serra dos Órgãos, a Área de Proteção Ambiental de Petrópolis e a RBA (Rodrigues et al. 2018).

Os resultados da influência de 2014 foram corroborados pelos focos de calor obtidos por satélites provenientes do Banco de Dados de Queimadas (INPE 2018), revelando que $96 \%$ dos focos ocorreram nesse mesmo ano no interior da RBA. A escassez de chuvas e a baixa umidade atmosférica foram apontadas como os principais fatores que influenciaram essas ocorrências em 2014 (Rodrigues et al. 2018, INPE 2018). Nos anos seguintes, 2015 e 2016, não houve ocorrências registradas; e, em 2017 e 2018, ocorreram poucos registros na $\mathrm{RBA}$.

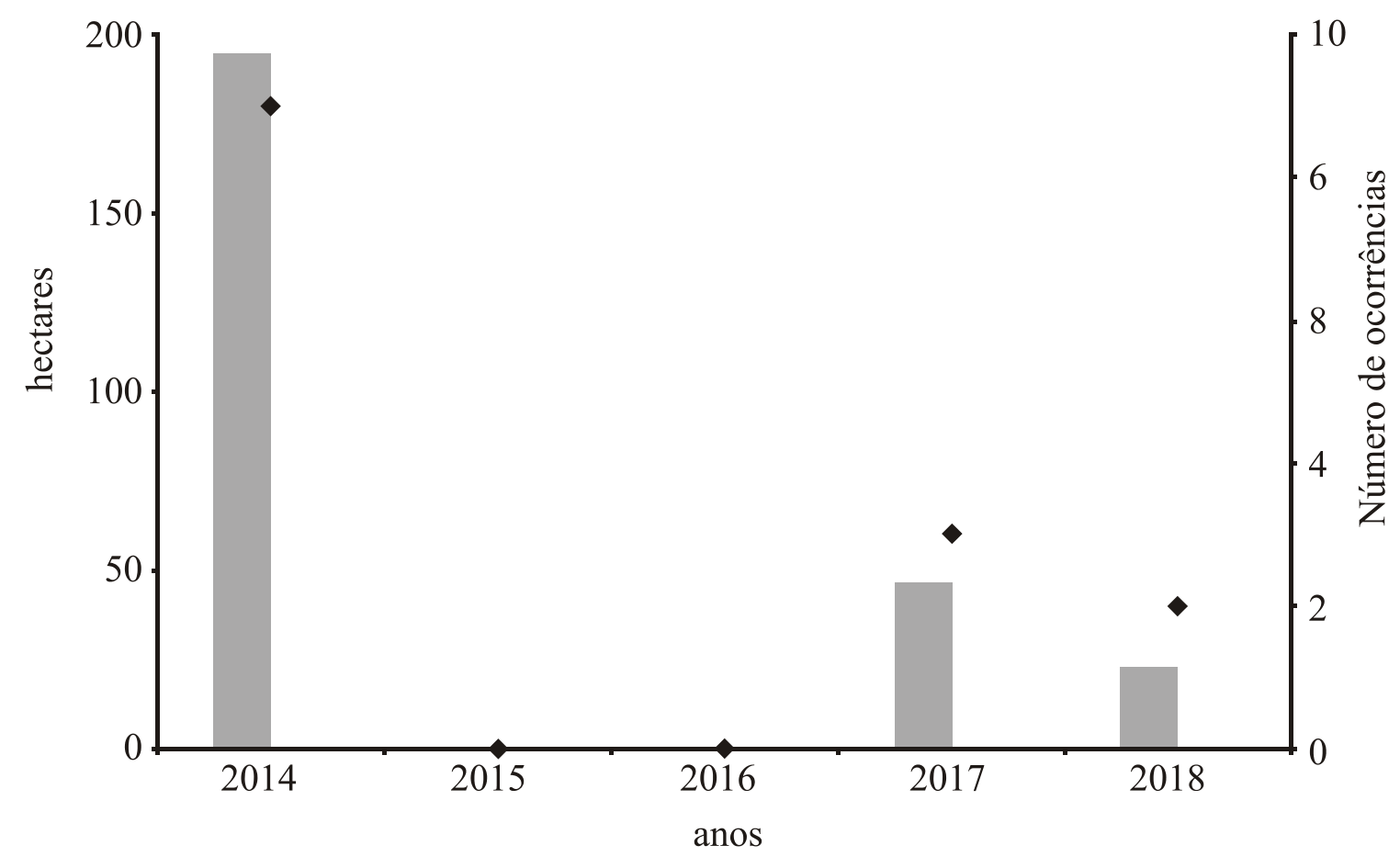

Figura 4 - Registros de incêndios florestais, por ano, na Reserva Biológica de Araras. Pontos pretos = número de ocorrências; barras cinzas = hectares atingidos na área da Reserva.

Fonte: Fábio T. Migliari (REBIO Araras). 
Nos anos de 2014, 2017 e 2018 foram queimados 187ha, 42 ha e 23ha, respectivamente, de acordo com os dados registrados nos ROIs da RBA (Figura 4). O setor que teve o maior número de incêndios florestais $(\mathrm{n}=7)$, com quase $60 \%$ das ocorrências, foi o Setor 4 , que possui o maior adensamento populacional. Esse fato pode contribuir para aumentar as chances de os indivíduos incendiários - por descuido ou mesmo por retaliação aos agentes ambientais - darem origem a incêndios florestais.

Pouco mais da metade dos incêndios $(n=8$; $57 \%$ ) ocorreu entre junho e outubro (Figura 5), época do ano com o menor volume de precipitação $e$, por outro lado, a maior frequência de queima do capim para renovação de pastagem na Mata Atlântica (Aximoff 2011, Aximoff et al. 2016b). A maioria das ocorrências de incêndios florestais no Brasil se concentra nesse mesmo período, que corresponde à estação mais seca do ano em quase todo o território (Lima et al. 2018).

\section{Ações de prevenção e combate}

Identificamos que as emissões das Notificações Preventivas contra Incêndios (NPIs) foram distribuídas ao longo de todo o ano, e todos os setores de monitoramento foram visitados. Contudo, foram distribuídos em 2014, 2017 e 2018 em maior número nos Setores 1 e 4, os mesmos que apresentaram maior quantidade de focos de calor em 2014 (INPE 2018). Em 2017, foi firmada uma parceria institucional com rondas pela zona de amortecimento e a distribuição de NPI em conjunto com o Corpo de Bombeiros Militar do Estado do Rio de Janeiro, o Instituto Estadual do Ambiente e a Prefeitura Municipal de Petrópolis, elevando para quase dez vezes o número de NPIs entregues, em relação ao ano anterior.

Além das NPIs, entre 2014 e 2016 foram realizadas palestras para mais de 10 mil pessoas, sobretudo alunos das escolas do entorno, chegando a uma média de pouco mais de 3 mil

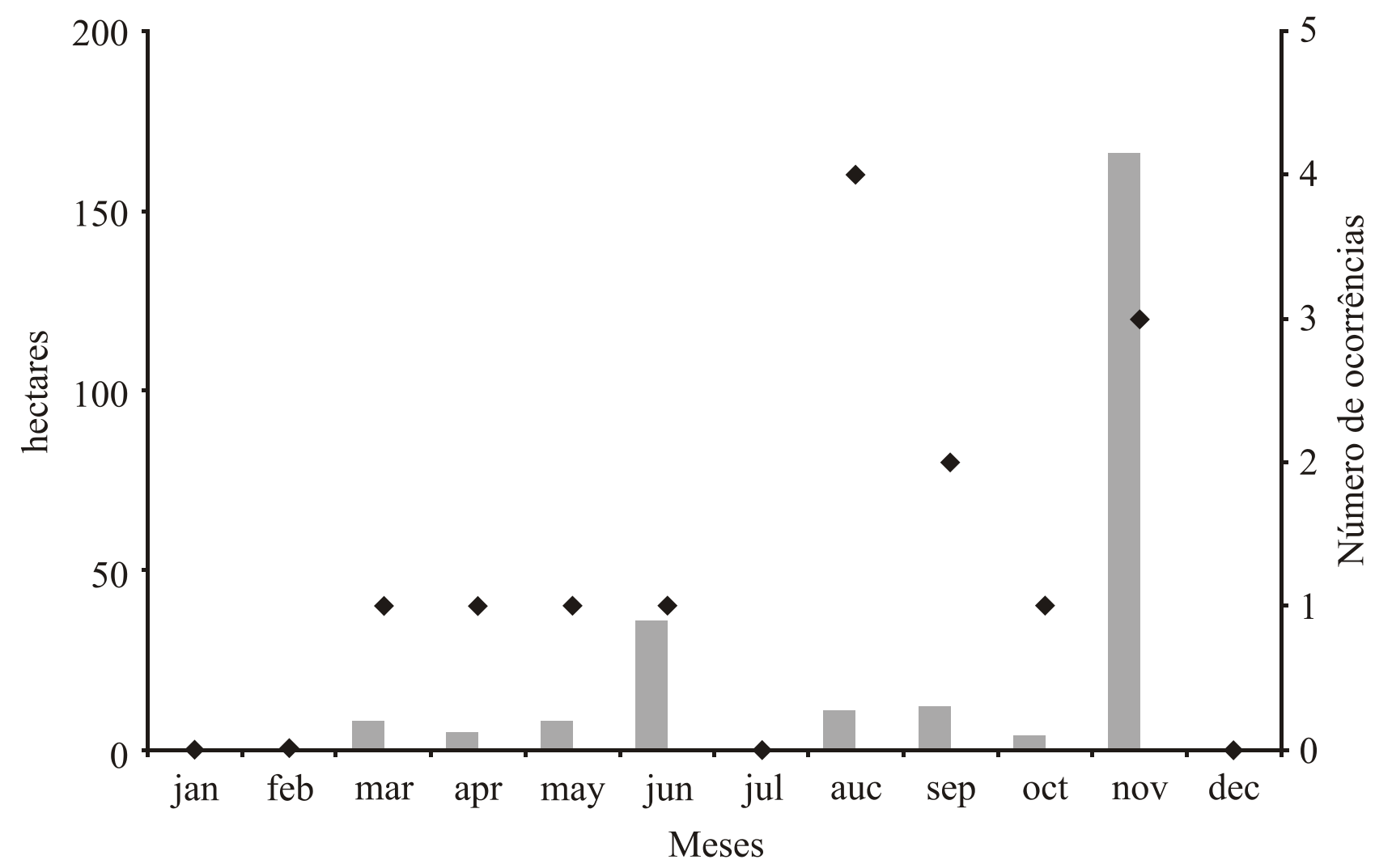

Figura 5 - Registros de incêndios florestais, por mês, na Reserva Biológica de Araras nos anos de 2014 a 2018. Pontos pretos = número de ocorrências; barras cinzas = hectares atingidos na área da Reserva. Fonte: Fábio T. Migliari (REBIO Araras). 
pessoas notificadas/avisadas/informadas por ano. Contudo, em 2017, o número de pessoas notificadas/avisadas/informadas ficou bem abaixo da média anteriormente citada (950 pessoas); e, em 2018, não foram repassados dados em relação às palestras $e$ aos participantes. As palestras $e$ as NPIs têm a finalidade de levar informação $e$ apresentar à população do entorno da UC as medidas preventivas de incêndios florestais, utilizando-se a educação ambiental para sensibilizar a população vizinha sobre o valor de todos os serviços ambientais prestados pela UC e o perigo do uso do fogo (Fagundes 2016), considerando que a maioria dos incêndios tem origem em ações negligenciais ou mesmo criminosas.

Os treinamentos de prevenção e combate a incêndios florestais são abertos à população $e$ aos prestadores de serviço de propriedades vizinhas. Equipes bem qualificadas, tanto nas técnicas de combate como no manuseio de ferramentas manuais e outros equipamentos usados na extinção do fogo, têm uma maior chance de dominar e controlar o fogo em menos tempo, reduzindo, assim, os danos causados (Motta 2008). Nos registros da RBA constam que ocorreu um treinamento anual em 2014, 2015 e 2018. Nos anos de 2014 e 2015, foi realizado um curso de Capacitação e Controle de Incêndios Florestais. Em 2018, foi realizado o Curso de Prevenção e Defesa Florestal (CPDF) no interior da RBA, contando com orientadores, professores, servidores e agentes de defesa ambiental do Instituto Estadual do Ambiente (INEA). Não foi possível mensurar o número de alunos inscritos nos cursos, pois não foi encontrado o registro.

Em algumas ações foi possível notar a descontinuidade de procedimentos ou uma menor atenção às informações geradas pela própria UC, levando à falta de dados para uma melhor análise das ações. Nos últimos anos houve, por exemplo, uma queda do número de palestras - atividade fundamental como ação preventiva, já que alcança grande número de alunos e familiares. Desta forma, é necessária a realização contínua dessa atividade. Vale ressaltar a importância de se utilizar e manter arquivado em local apropriado o Livro de Ocorrências para eventual consulta $e$ para anotações diárias, tais como os dados de temperatura e a umidade relativa do ar. A coleta dos dados de temperatura e umidade por meio de aparelho portátil apresenta maior eficácia para o cálculo do IRI personalizado pelos setores de monitoramento, e a coleta deve ser diária entre setembro e novembro. Em relação à NPI, considerada ação prioritária na busca de mais proteção ao interior da RBA, observou-se que seu conteúdoatendeà proposta de incrementaras ações no interior da RBA e na zona de amortecimento. De maneira geral, embora necessitem de alguns ajustes e retomadas de algumas atividades, as ações preventivas realizadas no período do estudo contribuíram para uma diminuição na ocorrência de incêndios. Portanto, a possibilidade da implementação da gestão do fogo, a partir de abordagens socialmente mais integradoras (manejo integrado do fogo), pode auxiliar a RBA na diminuição de incêndios florestais em seu interior e no entorno.

\section{Referências Bibliográficas}

Aximoff I, Rodrigues RC. Histórico dos incêndios florestais no Parque Nacional do Itatiaia. Ciência Florestal, 21(1): 83-92, 2011.

Aximoff I. O que perdemos com a passagem do fogo pelos campos de Altitude do Estado do Rio de Janeiro, Biodiversidade Brasileira, 1 (2): 180-200, 2011.

Aximoff I, Bovini MG, Fraga CN. Vegetação em Afloramentos Rochosos Litorâneos Perturbados por Incêndios na Região Metropolitana Fluminense, Estado do Rio de Janeiro, Biodiversidade Brasileira 6 (2): 149172, 2016.

Aximoff I, Nunes-Freitas AF \& Braga JMA. Regeneração natural pós-fogo nos campos de altitude no Parque Nacional do Itatiaia, sudeste do Brasil. Oecologia Australis, 20(2): 200-218, 2016b.

Bontempo GC, Lima GS, Ribeiro GA, Doula SM \& Jacovine LAG. Registro de ocorrência de incêndio (ROI): evolução, desafios e recomendações. Biodiversidade Brasileira 1(2): 247-263, 2011.

Fagundes VJ. 2016. Incêndios florestais em unidades de conservação de proteção integral da região metropolitana de Belo Horizonte, MG. UFLA. 122p.

Google Earth - Mapas. <https:/www.google.com/ earth/> Acesso em: 09/2019.

INEA - Instituto Estadual do Ambiente. 2010. Plano de Manejo Reserva Biológica de Araras. www.inea. rj.gov.br/cs/groups/public/documents/document/ zwew/mde5/ edisp/inea001976.pdf. Acesso em: 10/06/2017.

INPE - Instituto Nacional de Pesquisas Espaciais. 2007. Banco de Dados de Queimadas. São José dos Campos - São Paulo. <http://www.inpe.br/queimadas/ bdqueimadas/\# > . Acesso em: 09/2018. 
Koproski L, Batista AC \& Soares RV. Ocorrências de incêndios florestais no Parque Nacional de Ilha Grande - Brasil. Floresta, 34(2): 193-197, 2004.

Lima GS, Torres FTP, Costa AG, Félix GA \& Silva-Júnior MR. Avaliação da eficiência de combate aos incêndios florestais em unidades de conservação brasileiras. Floresta, 48(1): 113-122, 2018.

Magnanini A, Lardosa E, Marien JAS, Castro PFVB, Magalhães A, Monise AF, Bomtempo \& CBT, Wittur T. 2010. Roteiro metodológico para elaboração de planos de manejo: parques estaduais, reservas biológicas, estações ecológicas. INEA, Instituto Estadual do Ambiente, Rio de Janeiro. 116p.

Martinelli G. Nota sobre Worsleyarayneri (J.D. Hooker) Traub. \& Moldenke, espécie ameaçada de extinção. Rodriguésia, 36(58): 65-72, 1984.

Martinelli G, Martins E, Moraes M, Loyola R, Amaro R. (orgs.). 2018. Livro Vermelho da Flora Endêmica do Estado do Rio de Janeiro. Instituto de Pesquisas Jardim Botânico do Rio de Janeiro: Andrea Jakobsson, Rio de Janeiro. 456p.

Motta DS. 2008. Identificação dos fatores que influenciam no comportamento do fogo em incêndios florestais. UFRRJ, 24p.

Pereira AA, Pereira AJA, Morelli F, Barros DA, Weimar AJr., Soares F, Scolforo JR. Validação de focos de calor utilizados no monitoramento orbital de queimadas por meio de imagens TM. Cerne 18(2): 335-343, 2012.
QGIS userguide: versão 2.2. Disponível em < http:// docs.qgis.org/2.2/pdf/pt_BR/QGIS-2.2-User Guide-pt BR.pdf>. Acesso em: 20/12/2018.

Rezende CL, ScaranoFR, Assad ED, Joly CA, Metzger JP, Strassburg BBN, Tabareli M, Fonseca \& GA, Mittermeier RA. From hotspot to hotspot: An opportunity for the Brazilian Atlantic Forest. Perspect Ecol. Conserv., 16(4): 208-214, 2018.

Rodrigues JA, Libonati R, Peres LF \& Setzer A. 2018. Mapeamento de Áreas Queimadas em Unidades de Conservação da Região Serrana do Rio de Janeiro Utilizando o Satélite Landsat-8 durante a Seca de 2014, p. 318-327. In: Anuário do Instituto de Geociências 41, UFRJ.

Santos LMB, Alvarenga LJ \& Miranda MPS. 2017. A sinalização como instrumento de informação e proteção ambiental. $22^{\circ}$ Congresso Brasileiro de Direito Ambiental. Teses de Profissionais/Independent Papers, v. $1.802 \mathrm{p}$.

Tebaldi ALC. Ações de prevenção e combate aos incêndios florestais nas unidades de conservação estaduais do Espírito Santo. Floresta e Ambiente, 20(4): 538-549, 2013.

Torres FTP \& Lima GS. Forest Fire Hazard in the Serra do Brigadeiro State Park (MG). Floresta Ambiente 26 (2): e20170304, 2019.

Biodiversidade Brasileira - BioBrasil.

Edição temática: Diálogos entre a Academia e a Gestão de Áreas Protegidas:

Programa de Pós-Graduação Profissional - Biodiversidade em Unidades de Conservação

n. 2,2020

http://www.icmbio.gov.br/revistaeletronica/index.php/BioBR

Biodiversidade Brasileira é uma publicação eletrônica científica do Instituto Chico Mendes de

Conservação da Biodiversidade (ICMBio) que tem como objetivo fomentar a discussão e a disseminação de experiências em conservação e manejo, com foco em unidades de conservação e espécies ameaçadas.

ISSN: 2236-2886 